\title{
Measurement of model coefficients of skin sympathetic vasoconstriction
}

Citation for published version (APA):

Severens, N. M. W., van Marken Lichtenbelt, W., Frijns, A. J., Kingma, B. R., de Mol, B. A., \& van Steenhoven, A. A. (2010). Measurement of model coefficients of skin sympathetic vasoconstriction. Physiological Measurement, 31(1), 77-93. https://doi.org/10.1088/0967-3334/31/1/006

Document status and date:

Published: 01/01/2010

DOI:

10.1088/0967-3334/31/1/006

Document Version:

Publisher's PDF, also known as Version of record

Document license:

Taverne

Please check the document version of this publication:

- A submitted manuscript is the version of the article upon submission and before peer-review. There can be important differences between the submitted version and the official published version of record.

People interested in the research are advised to contact the author for the final version of the publication, or visit the DOI to the publisher's website.

- The final author version and the galley proof are versions of the publication after peer review.

- The final published version features the final layout of the paper including the volume, issue and page numbers.

Link to publication

\footnotetext{
General rights rights.

- You may freely distribute the URL identifying the publication in the public portal. please follow below link for the End User Agreement:

www.umlib.nl/taverne-license

Take down policy

If you believe that this document breaches copyright please contact us at:

repository@maastrichtuniversity.nl

providing details and we will investigate your claim.
}

Copyright and moral rights for the publications made accessible in the public portal are retained by the authors and/or other copyright owners and it is a condition of accessing publications that users recognise and abide by the legal requirements associated with these

- Users may download and print one copy of any publication from the public portal for the purpose of private study or research.

- You may not further distribute the material or use it for any profit-making activity or commercial gain

If the publication is distributed under the terms of Article $25 \mathrm{fa}$ of the Dutch Copyright Act, indicated by the "Taverne" license above, 


\section{Measurement of model coefficients of skin sympathetic vasoconstriction}

To cite this article: Natascha M W Severens et al 2009 Physiol. Meas. 3177

View the article online for updates and enhancements.

\section{Related content}

A model to predict patient temperature during cardiac surgery

N M W Severens, W D van Marken

Lichtenbelt, A J H Frijns et al.

- The relationship between local scalp skin temperature and cutaneous perfusion during scalp cooling

Francis-Paul E M Janssen,

Vinayakrishnan Rajan, Wiendelt Steenbergen et al.

Photoplethysmography and its application in clinical physiological measurement John Allen

\section{Recent citations}

- Differential impact in young and older
$\frac{\text { individuals of blue-enriched white light on }}{\text { circadian physiology and alertness during }}$
$\frac{\text { sustained wakefulness }}{\text { Virginie Gabel et al }}$
- Meth math: modeling temperature
$\frac{\text { responses to methamphetamine }}{\text { Yaroslav I. Molkov et al }}$
- The effects of physiological
$\frac{\text { thermorequlation on the efficacy of surface }}{\text { cooling for therapeutic hypothermia }}$
Mayank Kalra et al

The goal of ECS Sensors Plus, as a one-stop shop journal for sensors, is to advance the fundamental science and understanding of sensors and detection technologies for efficient monitoring and control of industrial processes and the environment, and improving quality of life and human health.

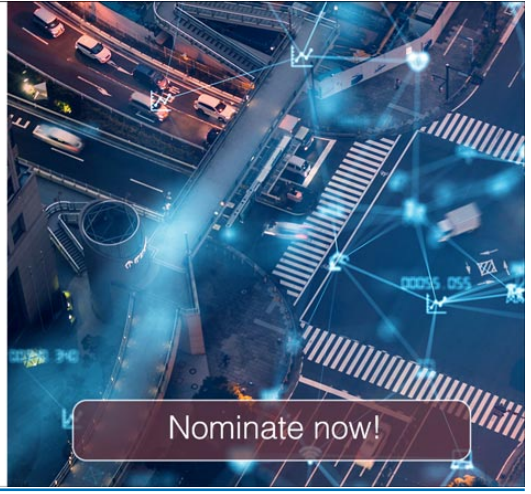




\title{
Measurement of model coefficients of skin sympathetic vasoconstriction
}

\author{
Natascha M W Severens, Wouter D van Marken Lichtenbelt, \\ Arjan J H Frijns, Boris R M Kingma, Bas A J M de Mol and \\ Anton A van Steenhoven \\ Department of Mechanical Engineering, Eindhoven University of Technology, PO Box 513, \\ 5600 MB Eindhoven, The Netherlands \\ E-mail: n.m.w.severens@tue.nl
}

Received 30 July 2009, accepted for publication 4 November 2009

Published 26 November 2009

Online at stacks.iop.org/PM/31/77

\begin{abstract}
Many researchers have already attempted to model vasoconstriction responses, commonly using the mathematical representation proposed by Stolwijk (1971 NASA Contractor Report CR-1855 (Washington, DC: NASA)). Model makers based the parameter values in this formulation either on estimations or by attributing the difference between their passive models and measurement data fully to thermoregulation. These methods are very sensitive to errors. This study aims to present a reliable method for determining physiological values in the vasoconstriction formulation. An experimental protocol was developed that enabled us to derive the local proportional amplification coefficients of the toe, leg and arm and the transient vasoconstrictor tone. Ten subjects participated in a cooling experiment. During the experiment, core temperature, skin temperature, skin perfusion, forearm blood flow and heart rate variability were measured. The contributions to the normalized amplification coefficient for vasoconstriction of the toe, leg and arm were $84 \%, 11 \%$ and $5 \%$, respectively. Comparison with relative values in the literature showed that the estimated values of Stolwijk and the values mentioned by Tanabe et al (2002 Energy Build. 34 637-46) were comparable with our measured values, but the values of Gordon (1974 The response of a human temperature regulatory system model in the cold PhD Thesis University of California, Santa Barbara) and Fiala et al (2001 Int. J. Biometeorol. 45 143159) differed significantly. With the help of regression analysis a relation was formulated between the error signal of the standardized core temperature and the vasoconstrictor tone. This relation was formulated in a general applicable way, which means that it can be used for situations where vasoconstriction thresholds are shifted, like under anesthesia or during motion sickness.
\end{abstract}

Keywords: vasoconstriction, modelling, thermoregulation, temperature, perfusion 


\section{Introduction}

Under normothermic conditions, the smooth muscle cells of the skin blood vessels are at a basal tone. During cold stress, a thermoregulatory reflex is initiated by increased noradrenergic vasoconstrictor tone. Both neural and local mechanisms are involved in this process.

Several researchers have already tried to model this vasoconstriction response. These vasoconstriction models can be implemented and coupled to thermo-physiological human models. Thermo-physiological models are mathematical models that mostly consist of (1) a passive part, describing the geometry and passive thermal properties of the body tissues, and (2) an active part, describing the thermoregulatory responses of the body. Thermo-physiological models are useful tools to predict body temperature responses of humans under different environmental conditions.

Generally, when vasoconstriction is represented in a mathematical way a system of thresholds, gains and maximum intensities is used. Researchers like Gordon (1974), Fiala et al (2001) and Tanabe et al (2002) developed models that were based on the work of Stolwijk (1971). The tentative expression that was used in the Stolwijk model, for describing skin blood flow, yields

$$
w_{\mathrm{b}}=\frac{w_{\mathrm{b}, 0}+a_{\mathrm{dl}} \mathrm{Dl}}{1+a_{\mathrm{cs}} \mathrm{Cs}} Q_{10}^{\frac{T-T_{0}}{10^{\circ} \mathrm{C}}}
$$

with $w_{\mathrm{b}}$ representing perfusion and $a_{\mathrm{dl}}$ and $a_{\mathrm{cs}}$ representing the amplification coefficients for vasodilation and vasoconstriction, respectively. $T$ is the local temperature and $\mathrm{Dl}$ and $\mathrm{Cs}$ denote the sympathetic vasodilation and vasoconstrictor tone, respectively. The magnitude of $\mathrm{Dl}$ and $\mathrm{Cs}$ depends on a temperature error signal which represents the difference between the actual temperature state and the temperature setpoint: $T-T_{0}$. Subscripts 0 denote the baseline value. The value of $Q_{10}$ equals 2 .

In equation (1), it can be seen that in the mathematical representation of blood flow, a division is made between the changes in perfusion induced by central sympathetic neural activity (the Cs- and Dl-terms) and by local temperature changes (the $Q_{10}^{\frac{T-T_{0}}{10^{\circ} \mathrm{C}}}$-term).

In the absence of clear measurement data, Stolwijk (1971) estimated the values for $a_{\mathrm{cs}}$ and Cs, that he used in his model. Later, Gordon (1974), Fiala et al (2001) and Tanabe et al (2002) also reported values for $a_{\mathrm{cs}}$ and Cs. In the work of Tanabe et al (2002), no justification is given for the used values. Gordon (1974) and Fiala et al (2001) explained the methods they employed for determining $a_{\mathrm{cs}}$ and Cs, but the methods that were used seem to be quite sensitive to errors. The basic idea of the methods of Gordon (1974) and Fiala et al (2001) was that $a_{\mathrm{cs}}$ and Cs were determined by using their own passive models (i.e. the description of the human geometry including passive heat transfer processes in the body and the heat interaction with the environment) and measured temperature data. They assumed that the difference in temperature between the model predictions and the measurement data could be fully attributed to active thermoregulation. By fitting the model to the measurement, they derived values for $a_{\mathrm{cs}}$ and Cs. An enormous drawback of this method is that when the passive model contains either programming or physiological errors, the active, thermoregulatory part will also be contaminated. When using those values in other thermal models, the correctness is questionable.

The present paper demonstrates a method to determine physiological values for the vasoconstriction amplification factors and vasoconstrictor tone in an independent way. Vasoconstriction values are derived for equation (1) by simultaneously performing measurements of local perfusion and temperature distribution in volunteers under uniform environmental conditions. These experimentally determined parameters provide a 
Table 1. Subject characteristics $(n=10)$. Values are given as mean \pm standard deviation

\begin{tabular}{lll}
\hline Subject characteristics & Mean \pm SD & Range \\
\hline Weight $(\mathrm{kg})$ & $77.7 \pm 11.0$ & $62-98$ \\
Height $(\mathrm{cm})$ & $186 \pm 8$ & $176-198$ \\
Age $($ years $)$ & $28.1 \pm 4.9$ & $20-34$ \\
BMI $\left(\mathrm{kg} \mathrm{m}^{-2}\right)$ & $22.5 \pm 2.6$ & $18.5-25.5$ \\
Fat $(\%)$ & $17.3 \pm 5.9$ & $9.6-24.2$ \\
BSA $\left(\mathrm{m}^{2}\right)$ & $2.0 \pm 0.2$ & $1.7-2.3$ \\
\hline
\end{tabular}

BMI is the body mass index.

BSA is the body surface area (Dubois and Dubois 1916).

physiological basis for a vasoconstriction model and are generally applicable in human thermophysiological models.

\section{Materials and methods}

\subsection{Subjects}

Ten healthy male Caucasian volunteers participated in this study. The study protocol was approved by the Maastricht University Medical Ethical Committee. Before participating in the study, all subjects signed an informed consent. The subject characteristics are shown in table 1. Body fat percentage was determined by skinfold measurements at the $\mathrm{m}$. biceps brachii, m. triceps brachii, subscapular and suprailiacal (Durnin and Womersley 1974).

\subsection{Protocol}

Subjects refrained from alcohol the day prior to the measurements. On the day of testing, the subjects took a light breakfast at 8:00 AM. They did not drink coffee or tea the morning before the test. From the moment the test began until the end of the test, the subjects were fasting. They arrived at the laboratory at 10:30 AM.

The subjects performed light exercise at a stepping platform. The exercise was ended when the fingertip-forearm gradient was $0^{\circ} \mathrm{C}$. In this way, a standardized situation was created prior to the start of the test, as the fingertip-forearm gradient is an indicator for thermoregulatory peripheral vasoconstriction (Rubinstein and Sessler 1990). Thereafter, all sensors were attached. Subsequently, the subjects entered a climate chamber (Schoffelen et al 1997). They were in a semisupine position for $3.5 \mathrm{~h}$, lying on a stretcher. In the room a small stable draft (70-80 $1 \mathrm{~min}^{-1}$ ) was present because of active ventilation, see the specification in Schoffelen et al (1997). The subjects were given the option to watch television during the test. An overview of the experimental time schedule is shown in figure 1.

During $1.5 \mathrm{~h}$ the room temperature was set to $27^{\circ} \mathrm{C}$, which is in the thermoneutral zone (Hardy and Stolwijk 1966). In this period, the temperature of the subject stabilized. After this period, the room temperature was changed to $20^{\circ} \mathrm{C}$. Under these conditions, no shivering response was expected on the basis of experiments performed by Hardy and Stolwijk (1966), which excludes disturbances in the measurements due to shivering effects. Moreover, the typical decrease in the mean skin temperature $\left(\sim 3{ }^{\circ} \mathrm{C}\right)$ agrees with the mean skin temperature decrease observed during aortic valve procedures performed at $30{ }^{\circ} \mathrm{C}$ (Severens et al 2007). The relative humidity was $55 \%$. 


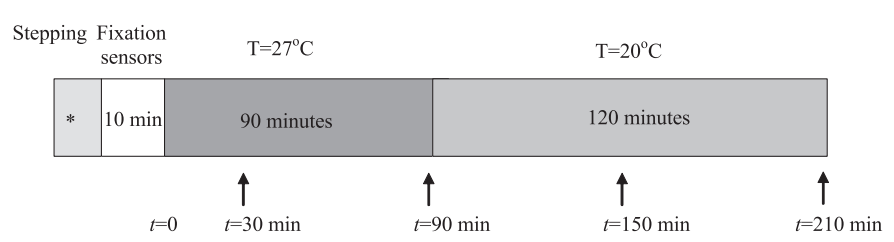

Figure 1. Time schedule of the experiment. * The volunteers used the stepping platform till the lower arm-fingertip gradient had become $0{ }^{\circ} \mathrm{C}$. $\uparrow$ denotes the time points where forearm blood flow was measured.

The subjects were wearing standard clothing consisting of underwear $(0.04$ clo $)$, a pair of short trousers $(0.06 \mathrm{clo})$ and a T-shirt ( 0.09 clo). The face, lower arms, lower legs, hands and feet were directly exposed to the environment.

\subsection{Temperature measurements}

Skin temperatures were measured continuously at $1 \mathrm{~min}$ intervals by sensors (iButton type DS192H, Maxim/Dallas Semiconductor Corp., USA) placed at the head, lower arm, upper arm, hand, fingertip, foot, toe, lower leg (anterior and posterior), thigh (anterior and posterior), chest, abdomen, scapula and lumbar. This type of sensor has recently been evaluated for studies in humans by Van Marken Lichtenbelt et al (2006). They reported a mean accuracy of $0.09{ }^{\circ} \mathrm{C}$, with a maximum deviation of $0.4{ }^{\circ} \mathrm{C}$.

The mean skin temperature is calculated by using the 12-point-weighted formula of Hardy and Dubois (Mitchell and Wyndham 1969), which in general has good agreement over a large range of ambient temperatures, especially under cold conditions:

$$
\begin{aligned}
T_{\text {skin }}=0.07 T_{\text {head }}+0.0875 T_{\text {chest }}+0.0875 T_{\text {abdomen }}+0.0875 T_{\text {scapula }}+0.0875 T_{\text {lumbar }} \\
+0.14 T_{\text {lower arm }}+0.05 T_{\text {hand }}+0.095 T_{\text {thigh anterior }}+0.095 T_{\text {thigh posterior }} \\
+0.065 T_{\text {calf anterior }}+0.065 T_{\text {calf posterior }}+0.07 T_{\text {foot }} .
\end{aligned}
$$

The rectal temperature was measured continuously by a thermistor-probe (YSI probes, tip diameter $3.3 \mathrm{~mm}$, series 402, Yellow Springs Instruments, Ohio, USA) inserted at least $10 \mathrm{~cm}$.

The fingertip-forearm gradient, which was used as an index of thermoregulatory peripheral vasoconstriction (Rubinstein and Sessler 1990), was measured with an infrared thermometer (Infrared Tympanic Thermometer, First Temp Genius, Sherwood-Davis \& Geck, $\mathrm{UK}$ ) prior to entering the respiration chamber and by means of iButtons from the start to the end of the experiment.

\subsection{Skin perfusion}

Cutaneous blood flows under the big toe, at the ventral side of the lower leg (at the extensor digitorum longus muscle) and at the middle of the forearm (at the palmaris longus) were recorded using laser Doppler flowmetry (LDF). A two-channel laser Doppler flowmeter and a one-channel laser Doppler flowmeter were used (both Perimed 4001, with a $780 \mathrm{~nm}$ laser diode, $0.25 \mathrm{~mm}$ fibre separation). The probes were calibrated with PF 1000 calibration equipment (Perimed $\mathrm{AB}$ ). The sample rate was set to $8 \mathrm{~Hz}$ using a time constant of $0.2 \mathrm{~s}$. Before starting the measurement the device was left for at least $30 \mathrm{~min}$ to warm up. All measurements were performed with a standard probe (Probe 408, Perimed AB). Probes were placed in a probe 
holder (PH 08-1, Perimed AB) and mounted with double-sided adhesive tape. Temperature sensors were placed within $1 \mathrm{~cm}$ distance from the laser Doppler probes.

Laser Doppler flowmetry does not provide absolute measurements of flow. Differences in baseline values are therefore likely. However, by normalizing individual perfusion responses by individual baseline values, perfusion indexes are obtained that are comparable within subjects (Kellogg et al 1998). This makes laser Doppler flowmetry a suitable method for this study, as for further analysis normalized values are used (for model details see section 2.7). All skin perfusion data in this study are presented as filtered signals, without subtracting the biological zero measured during occlusion. This decision was based on practical (Kernick et al 1999, Leahy et al 1999) as well as theoretical issues (Zhong et al 1998), see also Severens (2008).

\subsection{Forearm blood flow}

Forearm blood flow was measured by venous occlusion plethysmography (EC5R Strain Gauge and Photo Plethysmograph, Hokanson, Washington, USA) using mercury-in-silastic strain gauges applied to the widest part of the forearm. During measurement periods, the hand circulation was occluded by rapid inflation of a paediatric sphygmomanometer cuff, placed around the wrist, to a pressure of $200-220 \mathrm{mmHg}$. In this way, forearm blood flow was assessed without interference of hand circulation. The proximate cuff placed around the upper arm was automatically inflated (and deflated) to $45 \mathrm{mmHg}$ to achieve venous occlusion (E20 Rapid Cuff Inflator, Hokanson, Washington, USA) and obtain plethysmographic recordings. A complete set of forearm strain gauges was available, ranging from 16 to $30 \mathrm{~cm}$ in $2 \mathrm{~cm}$ increments. Measurements took place at four time points with an interval of $1 \mathrm{~h}$ (figure 1). A measurement period lasted about $1.5 \mathrm{~min}$, where the cuff was inflated every $4 \mathrm{~s}$. The chart recorder range gain was set to $0.1 \% \mathrm{~cm}^{-1}$. The flow rate after analysing the slope of the plethysmograph readings is reported in percentage volume change per minute, which equals $\mathrm{ml}$ blood/(100 $\mathrm{ml}$ tissue $\mathrm{min})$. Varying conditions of ambient temperatures were compensated by the electrical circuit in the device. In the analysis of the plethysmography output, no further adjustments for thermal compensation were therefore required.

\section{6. $E C G$}

Heart rate variability was calculated from ECG data recorded using an ambulatory Holter ECG monitor (GE Health Care, Freiburg, Germany). Heart rate variability indirectly quantifies the sympathetic contribution to heart rate and can be considered to be a measure for sympathetic function. The very low frequency component ( VLF $<0.04 \mathrm{~Hz}$ ) of the $\mathrm{R}-\mathrm{R}$ interval spectrum is thought to be associated with thermoregulation (Brenner et al 1997, Matsumoto et al 2001). Digital data obtained from the ECG were analysed using fast Fourier transformations as described by Oida et al (1997).

The skin surface at the electrode side was lightly rubbed and cleansed thoroughly with alcohol. Seven electrodes were attached to the skin and connected according to the AVF leads. The measurement data were analysed for three time intervals: (1) 60-90 min (2) 120-150 min (3) 180-210 min.

\subsection{Data analysis}

Laser Doppler results were analysed as a running average of $60 \mathrm{~s}$ epochs, to filter out motion artefacts. The average temperature and perfusion values at $t=30$ to $t=35 \mathrm{~min}$ were used as 
baseline values $T_{0}$ and $w_{\mathrm{b}, 0}$, respectively. Then the temperature difference $\left(\Delta T_{\mathrm{i}}=T_{\mathrm{i}}-T_{\mathrm{i}, 0}\right)$ and the relative perfusion $\left(\frac{w_{\mathrm{b}, \mathrm{i}}}{w_{\mathrm{b}, \mathrm{i}, 0}}\right)$ for a body part $\mathrm{i}$ were related, using the following equation (Janssen et al 2007):

$$
\frac{w_{\mathrm{b}, \mathrm{i}}}{w_{\mathrm{b}, \mathrm{i}, 0}}=Q_{\mathrm{fit}, \mathrm{i}}^{\frac{\Delta T_{\mathrm{i}}}{10^{\circ \mathrm{C}}}}
$$

$Q_{\text {fit,i }}$ was determined with the help of the perfusion and temperature data and equation (3). Subscript i represents the toe, lower leg or arm.

The structure of the relation formulated by Stolwijk (1971) was kept:

$$
w_{\mathrm{b}}=\frac{w_{\mathrm{b}, 0}+a_{\mathrm{dl}} \mathrm{Dl}}{1+a_{\mathrm{cs}} \mathrm{Cs}} Q_{10}^{\frac{\Delta T_{\mathrm{i}}}{10^{\circ} \mathrm{C}}} \text {. }
$$

When vasodilation is absent $(\mathrm{Dl}=0)$, equation $(4)$ reduces to

$$
\frac{w_{\mathrm{b}}}{w_{\mathrm{b}, 0}}=\frac{1}{1+a_{\mathrm{cs}} \mathrm{Cs}} Q_{10}^{\frac{\Delta T_{\mathrm{i}}}{10^{\circ \mathrm{C}}}}
$$

Equation (3) should be identical to equation (5) for each body part i. This leads to the following relation for sympathetic vasoconstriction tone $(\mathrm{Cs})$ :

$$
\mathrm{Cs}=\frac{1}{a_{\mathrm{cs}, \mathrm{i}}}\left({\frac{Q_{\mathrm{fit}, \mathrm{i}}}{Q_{10}}}^{\frac{-\left(\Delta T_{1}\right)}{10^{\circ} \mathrm{C}}}-1\right)
$$

with $a_{\mathrm{cs}, \mathrm{i}}$ representing the amplification factor for vasoconstriction. The following set of equations was solved at each time point:

$$
\begin{aligned}
& \text { Cs } a_{\mathrm{cs}, \text { toe }}={\frac{Q_{\mathrm{fit}, \mathrm{toe}}}{Q_{10}}}^{\frac{-\Delta T_{\mathrm{toc}}}{10^{\circ} \mathrm{C}}}-1 \\
& \operatorname{Cs} a_{\mathrm{cs}, \text { leg }}={\frac{Q_{\mathrm{fit}, \text { leg }}}{Q_{10}}}^{\frac{-\Delta T_{\mathrm{leg}}}{10^{\circ} \mathrm{C}}}-1 \\
& \operatorname{Cs} a_{\mathrm{cs}, \text { arm }}={\frac{Q_{\mathrm{fit}, \mathrm{arm}}}{Q_{10}}}^{\frac{-\Delta T_{\mathrm{arm}}}{10^{\circ} \mathrm{C}}}-1
\end{aligned}
$$

where Cs is the central vasoconstrictor tone, and therefore independent of the location. It is chosen to bound the value for $\mathrm{Cs}$ to a maximum value of 1 at the point where vasoconstriction is the highest and skin temperature is the lowest. Note that this choice differs from the choices made by Stolwijk (1971), Fiala et al (2001) and Tanabe et al (2002). Those authors chose the sum of the amplification coefficients of all body parts equal to $1: \sum_{i=1}^{n} a_{\mathrm{cs}, \mathrm{i}}=1$. As this makes the model less flexible for changing the number of body parts, this strategy was not followed here. In addition, as only three body parts were measured, it was not logical to normalize the sum of those three amplification coefficients to 1 .

\subsection{Statistics}

Results are expressed throughout as means with standard deviation. Plethysmography, heart rate variability and temperature measurements were analysed with a paired $t$-test. Results are considered statistically significant when $P<0.05$.

Values for $Q_{\text {fit,i }}$ were derived using temperature and perfusion data, equation (3) and linear regression analysis after log-transformation. Control equations for vasoconstriction tone as a function of an error signal were derived using nonlinear regression analysis. The statistical analyses were made with the help of Statgraphics Plus 5.1. 
(a)

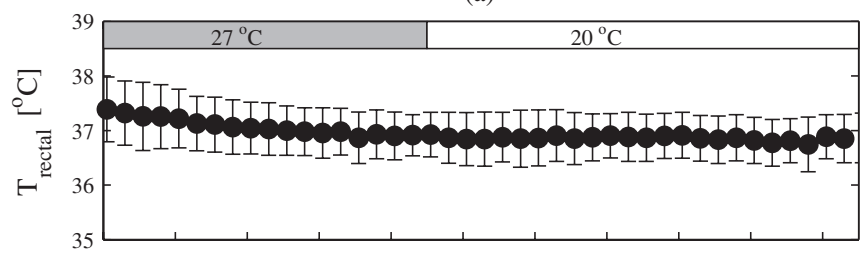

(b)

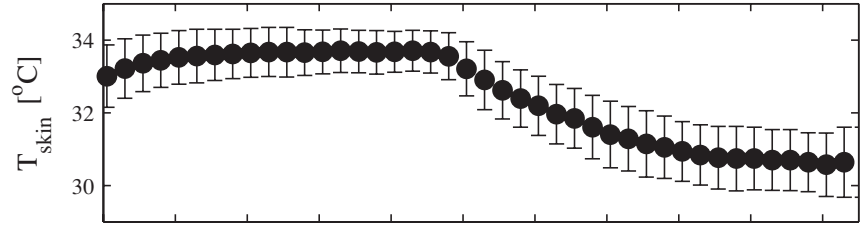

(c)

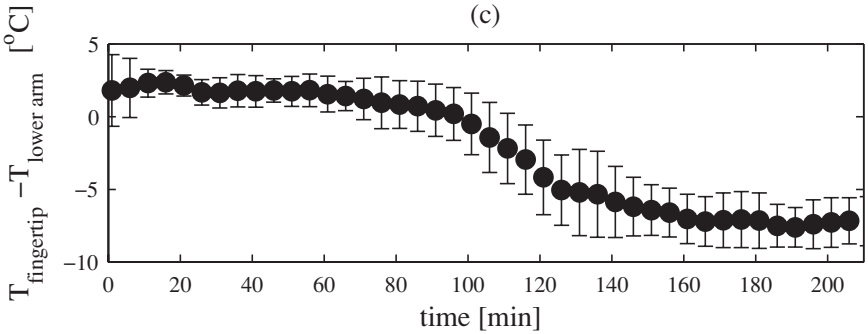

Figure 2. (a) Core temperature during the experiment. (b) Mean skin temperature. (c) Fingertipforearm temperature gradient. Results are mean values (SD).

\section{Results}

\subsection{Temperature}

Temperature fluctuations in the climate chamber stayed within $1{ }^{\circ} \mathrm{C}$, when the temperatures was set to $27^{\circ} \mathrm{C}$. When switching to the cool stage at $t=90 \mathrm{~min}$, it took about $40 \mathrm{~min}$ before a temperature of $20^{\circ} \mathrm{C}$ was reached. Then temperature stayed within a $1.5^{\circ} \mathrm{C}$ range.

Rectal temperature fluctuations due to changes in environmental temperature conditions were about $0.1{ }^{\circ} \mathrm{C}$ (see figure 2(a)). At the beginning of the measurement period, rectal temperature decreased by about $0.3{ }^{\circ} \mathrm{C}$, which is probably caused by the transition from standing position during exercise to semisupine position. Temperature differences at the end of the warm stage ( $t=90 \mathrm{~min}$, the baseline value), at $t=150 \mathrm{~min}$ and at the end of the cold stage $(t=210 \mathrm{~min})$ were analysed with a paired $t$-test, see table 2 . No statistical difference in the mean rectal temperature was observed during the experiment.

At $t=90 \mathrm{~min}$, the mean skin temperature immediately decreased (figure 2(b)). Paired $t$-test results revealed that the mean skin temperature at $t=150$ and $t=210 \mathrm{~min}$ was significantly lower than the mean skin temperature at $t=90 \mathrm{~min}$.

The fingertip-lower arm gradient is shown in figure 2 (c). A $4{ }^{\circ} \mathrm{C}$ gradient identifies significant vasoconstriction (Rubinstein and Sessler 1990). Also, a significant rise in the very low frequency (VLF) components of the heart rate variability is found between the warm and cold periods (see table 2). However, no significant effect on autonomic balance was observed (LF/HF). Blood pressure was stable during the testing period. Accordingly, it is concluded 
Table 2. Summarized temperature and perfusion data: mean (SD).

\begin{tabular}{llllll}
\hline & $\begin{array}{l}t=90 \mathrm{~min} \\
\text { (baseline) }\end{array}$ & $t=150 \mathrm{~min}$ & $P_{90-150}$ & $t=210 \mathrm{~min}$ & $P_{90-210}$ \\
\hline$T_{\text {core }}\left({ }^{\circ} \mathrm{C}\right)$ & $36.92(0.41)$ & $36.92(0.42)$ & 0.91 & $36.86(0.44)$ & 0.53 \\
$T_{\text {skin }}\left({ }^{\circ} \mathrm{C}\right)$ & $33.7(0.6)$ & $31.2(0.9)$ & $<0.001^{*}$ & $30.6(1.0)$ & $<0.001^{*}$ \\
$T_{\text {fingertip }}-T_{\text {lowerarm }}\left({ }^{\circ} \mathrm{C}\right)$ & $0.6(1.7)$ & $-6.2(1.9)$ & $<0.001^{*}$ & $-7.1(1.6)$ & $<0.001^{*}$ \\
Forearm blood flow $\left[\frac{\mathrm{ml}}{100 \mathrm{mlmin}}\right]$ & $4.2(1.8)$ & $2.7(1.4)$ & $0.006^{*}$ & $2.2(1.3)$ & $0.001^{*}$ \\
VLF power $\left(\mathrm{ms}^{2}\right)$ & $2198(1231)$ & $3719(2458)$ & $0.036^{*}$ & $3568(1313)$ & $0.011^{*}$ \\
LF/HF $[-]$ & $3.03(1.28)$ & $3.30(1.65)$ & 0.24 & $2.86(1.20)$ & 0.13 \\
\hline
\end{tabular}

${ }^{*}$ Statistical significant result $(P<0.05)$.

VLF is the very low frequency component of the heart rate variability.

LF is the low-frequency component of the heart rate variability.

$\mathrm{HF}$ is the high-frequency component of the heart rate variability.

that in the experiment an evident vasoconstriction response was present that can be used to derive the required parameters.

\subsection{Perfusion results}

3.2.1. Plethysmography results. For the analysis only pulses were used that looked acceptable, i.e. with a clear ascending slope, after visual inspection (instructions were followed according to the Hokansson-NIVP3 software manual). The cuff artefact, the abrupt rise in limb volume that sometimes occurred due to reflux of blood when the cuff is inflated, was always excluded from the analysis. Paired $t$-tests reveal that forearm blood flow was significantly different at $t=150 \mathrm{~min}(P=0.006)$ and $t=210 \mathrm{~min}(P=0.001)$ from the baseline blood flow (at $t=90 \mathrm{~min}$ ), see table 2 .

3.2.2. Skin perfusion Typical time traces for local skin perfusion and skin temperature at the measured spots are shown in figure 3. It is seen that when local temperature decreased, local skin perfusion decreased simultaneously.

In the perfusion signal sometimes peaks occur, as is seen in the arm signal in figure 3 . One explanation is that those peaks are caused by movement artefacts. Another explanation is that the processing bandwidths of the laser Doppler flowmeters, that were used, are not tailored to adaptively detect the most important frequency range. Ideally, the lower cutoff frequency should be chosen in such a way that low-frequency artefacts due to tissue motion are filtered out and that the higher cutoff frequency filters out the high-frequency noise (cf Obeid et al (1990) and Chen et al (2004)). However, since in the remaining periods the signal seems to be quite stable and the periods with peaks are short and the effect on the end result is small, it is decided to include the signals in further analyses.

\subsection{Relation between perfusion/temperature}

Relation (3) was analysed with the help of laser Doppler perfusion data and temperature data taken from $t=30$ to $210 \mathrm{~min}$. The first $30 \mathrm{~min}$ was not taken into account, as the temperature and perfusion during that period were stabilizing.

For each individual subject, temperature and perfusion data of the toe, lower leg and arm were fitted to equation (3). A linear fitting procedure was used after log-transformation. Also, 

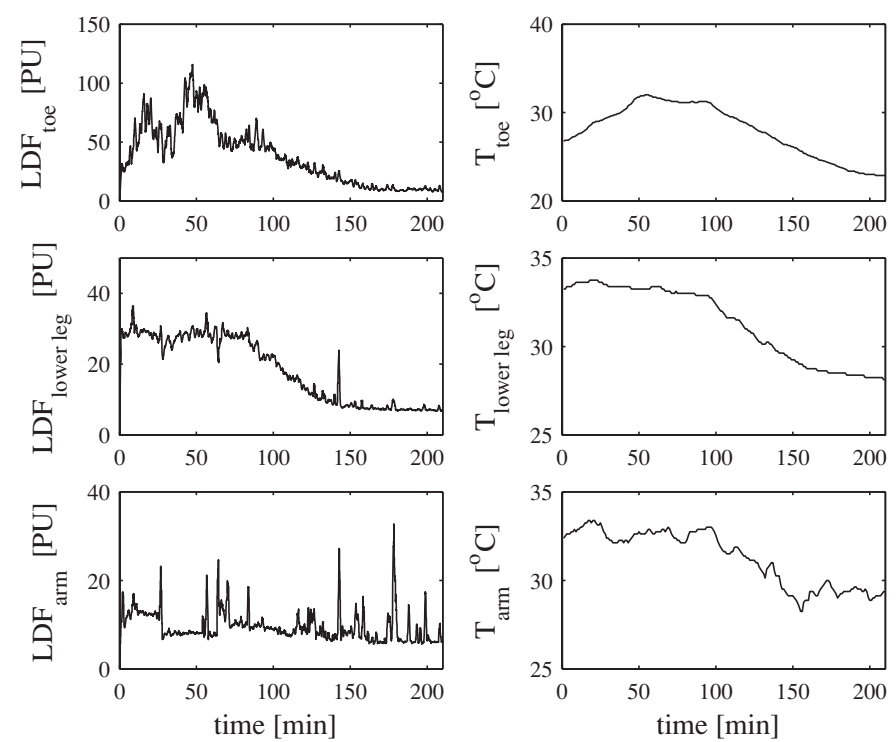

Figure 3. Time traces of one subject for skin perfusion measured with LDF (presented in dimensionless perfusion units (PU)) and skin temperature for toe, lower leg and arm, respectively.

Table 3. Results of individual fits to equation (3). The results are normalized at 1. A linear fitting procedure is used after log-transformation.

\begin{tabular}{ccclccc}
\hline Subject & $Q_{\text {fit,toe }}$ & $R^{2}$ & $Q_{\text {fit,leg }}$ & $R^{2}$ & $Q_{\text {fit, arm }}$ & $R^{2}$ \\
\hline 1 & 14.9 & 0.91 & 9.7 & 0.91 & 44.3 & 0.50 \\
2 & 15.7 & 0.92 & 18.2 & 0.96 & 1.3 & 0.05 \\
3 & 10.6 & 0.84 & 2.8 & 0.82 & 7.7 & 0.45 \\
4 & 15.6 & 0.96 & 3.3 & 0.90 & 88.2 & 0.73 \\
5 & 9.9 & 0.85 & 10.8 & 0.94 & 1.4 & 0.11 \\
6 & 10.6 & 0.86 & 3.1 & 0.77 & 0.04 & 0.00 \\
7 & 15.4 & 0.92 & 6.5 & 0.68 & 2.5 & 0.12 \\
8 & 28.5 & 0.91 & 5.3 & 0.78 & 1.5 & 0.16 \\
9 & 16.6 & 0.87 & 3.8 & 0.89 & 3.7 & 0.61 \\
10 & 6.68 & 0.84 & 210.6 & 0.85 & 2.5 & 0.57 \\
All & $14.2 \pm 0.1$ & 0.87 & $5.9 \pm 0.07^{\mathrm{a}}$ & $0.69^{\mathrm{a}}$ & $3.9 \pm 0.11$ & 0.20 \\
\hline
\end{tabular}

${ }^{a}$ Data from subject 10 were not taken into account in the average fit, because it deviated a lot from the other subjects.

the averaged data of all ten subjects were used to fit equation (3). Best fits and fitting statistics of all individuals and the mean value of all subjects are detailed in table 3 . In figure 4 the mean perfusion-temperature curves are shown for the three locations. Large intersubject variability was observed. Toe temperature drop varied between 8 and $12{ }^{\circ} \mathrm{C}$, lower leg temperature decreased between 4 and $6{ }^{\circ} \mathrm{C}$ and the decrease in arm temperature was between 3 and $6{ }^{\circ} \mathrm{C}$. 

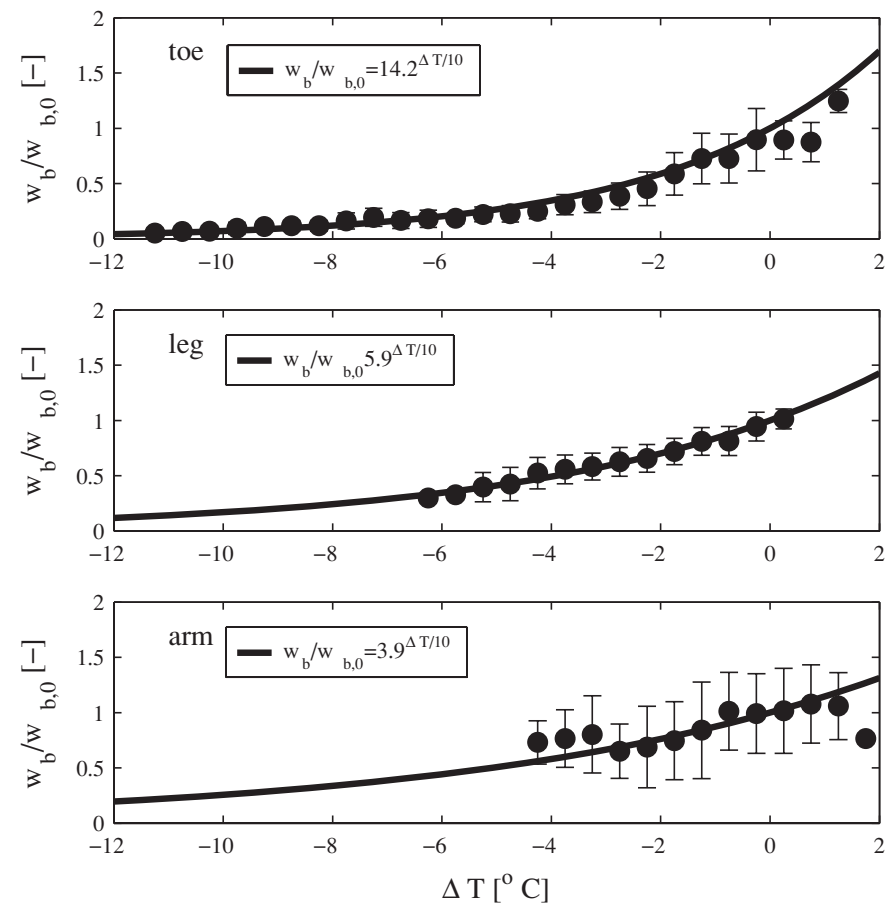

Figure 4. Mean perfusion-temperature curves (SD) of all volunteers. From top to bottom: toe, lower leg and arm.

\subsection{Experimentally determined amplification coefficients and sympathetic vasoconstriction tone}

3.4.1. Amplification coefficients. From the fingertip-lower arm gradient, shown in figure 2(c), it is seen that vasoconstriction started around $t=90 \mathrm{~min}$ and lasted till the end of the measurement $(t=210 \mathrm{~min})$. It is observed that skin temperatures stabilized towards the end of the cold period. As mentioned in section 2.7, the maximum value of Cs was chosen to be 1 . The minimum value for $\mathrm{Cs}$ is 0 , as negative values would indicate vasodilation. Therefore, Cs was set to 1 at the end of the cold period because vasoconstriction is expected to be largest at the time that skin temperatures were lowest. The value $a_{\mathrm{cs}, \mathrm{i}}$ is taken as a constant, in similarity to studies performed by other researchers (Stolwijk 1971, Gordon 1974, Fiala et al 2001, Tanabe et al 2002). With the help of equations (7)-(9) and the assumption that $\mathrm{Cs}=$ 1 at $t=210 \mathrm{~min}$, the amplification coefficients for the toe, leg and arm were determined for all subjects. This resulted in $a_{\mathrm{cs}, \text { toe }}=7.42 \pm 3.24, a_{\mathrm{cs}, \mathrm{leg}}=1.00 \pm 0.64$ and $a_{\mathrm{cs} \text {, arm }}=0.46 \pm 0.67$, see table 4.

The $a_{\mathrm{cs}}$ results obtained in the current study can be compared to the values used in other models (Stolwijk 1971, Gordon 1974, Fiala et al 2001, Tanabe et al 2002) by expressing them as percentages, see table 5. This is necessary as not all authors use the same sum of relative values of the three body parts. In the current study, relative values of $84 \%, 11 \%$ and $5 \%$ for the toe, leg and arm, respectively were found. It is seen that the feet in our experiment contribute more, while the arm contributes less to the vasoconstriction response than other models suggest (see tables 4 and 5). The sum of the amplification coefficients for all body parts $\left(\sum_{i=1}^{n} a_{\mathrm{cs}, \mathrm{i}}\right)$ of Stolwijk (1971), Fiala et al (2001) and Tanabe et al (2002) was always equal to 1 , while the sum of our amplification factors is not necessarily 1 . In this way, the 
Table 4. Mean values obtained for vasoconstriction amplification coefficients in the current study. The relative values are also given to make comparison easier.

\begin{tabular}{lcc}
\hline & \multicolumn{2}{c}{ Severens Range Cs: $0-1$} \\
\cline { 2 - 3 } & Absolute & Relative \\
\hline$a_{\text {cs,toe }}$ & $7.42 \pm 3.24$ & $84 \% \pm 36 \%$ \\
$a_{\text {cs,leg }}$ & $1.00 \pm 0.64$ & $11 \% \pm 7 \%$ \\
$a_{\text {cs,arm }}$ & $0.46 \pm 0.67$ & $5 \% \pm 7 \%$ \\
\hline
\end{tabular}

Table 5. Vasoconstriction amplification coefficients used by Stolwijk (1971), Fiala et al (2001), Tanabe et al (2002) and Gordon (1974). The relative values are also given to make comparison with the current study easier.

\begin{tabular}{|c|c|c|c|c|c|c|c|c|}
\hline & \multicolumn{2}{|c|}{$\begin{array}{l}\text { Stolwijk (1971) } \\
\text { Range Cs: 0-18 }\end{array}$} & \multicolumn{2}{|c|}{$\begin{array}{l}\text { Fiala } \text { et al (2001) } \\
\text { Range Cs: } 0-110\end{array}$} & \multicolumn{2}{|c|}{$\frac{\text { Tanabe et al (2002) }}{\text { Range Cs: unknown }}$} & \multicolumn{2}{|c|}{$\begin{array}{c}\text { Gordon (1974) } \\
\text { Range Cs: unknown }\end{array}$} \\
\hline & Absolute & Relative & Absolute & Relative & Absolute & Relative & Absolute & Relative \\
\hline$a_{\mathrm{cs}, \text { toe }}$ & $0.35^{\mathrm{a}}$ & $78 \%$ & $0.3765^{\mathrm{a}}$ & $48 \%$ & $0.152^{\mathrm{a}}$ & $78 \%$ & $0.2961^{\mathrm{a}}$ & $38 \%$ \\
\hline$a_{\mathrm{cs}, \operatorname{leg}}$ & 0.05 & $11 \%$ & 0.20 & $26 \%$ & 0.022 & $11 \%$ & 0.2104 & $27 \%$ \\
\hline$a_{\mathrm{cs}, \mathrm{arm}}$ & 0.05 & $11 \%$ & 0.1945 & $25 \%$ & 0.022 & $11 \%$ & 0.2700 & $35 \%$ \\
\hline
\end{tabular}

a This value refers to the amplification coefficient of the whole foot.

values for $a_{\mathrm{cs}, \mathrm{i}}$ are independent of the number of body parts that are modelled. Also Gordon (1974) did not normalize his amplification coefficients to 1.

The range of Cs obtained in the current study cannot be compared to other studies. For instance, the range in the model of Fiala et al (2001) under these conditions for Cs is between 0 and 110. The Cs values of the model of Stolwijk (1971) was between 0 and 18. The range of Tanabe et al (2002) and Gordon (1974) could not be calculated as not all required temperatures were available for calculating Cs with their model (namely pelvis, shoulder, head, face, neck data). However, it is possible to compare the products of the maximum value for $a_{\mathrm{cs}, \mathrm{i}} \mathrm{Cs}$ found in this study to the products of Stolwijk (1971) and Fiala et al (2001). In our study the products of $a_{\mathrm{cs}, \mathrm{i}} \mathrm{Cs}$ are $7.42 \pm 3.24,1.00 \pm 0.64$ and $0.46 \pm 0.67$ for the toe, leg and arm, respectively. The products of $a_{\mathrm{cs}, \mathrm{i}} \mathrm{Cs}$ of Stolwijk (1971) are 6.3, 0.9 and 0.9, respectively. According to Fiala et al (2001), the products are 41, 22 and 21, respectively.

It can be seen that the current measured values (both the normalized values for $a_{\mathrm{cs}, \mathrm{i}}$ and the product $a_{\mathrm{cs}, \mathrm{i}} \mathrm{Cs}$ ) are very close-within the intersubject variability - to the tentative values proposed by Stolwijk (1971), but deviate considerably from the values used by Fiala et al (2001) and Gordon (1974). The normalized values for $a_{\mathrm{cs}}$ of current measurements are also within the range of Tanabe et al (2002)'s values.

3.4.2. Vasoconstrictor tone: Cs. The transient vasoconstrictor tone was determined for all subjects. Results are given in figure 5. A distinct increase in vasoconstrictor tone is visible starting from $t=90 \mathrm{~min}$.

3.4.3. Evolvement of a vasoconstriction tone relation. The vasoconstrictor tone showed a clear rise; see figure 5. According to the basic engineering control concept, the vasoconstrictor tone is initiated by a so-called error signal. Although there is no general consensus if such a regulation of physiological systems exists in reality or if core temperature is maintained 


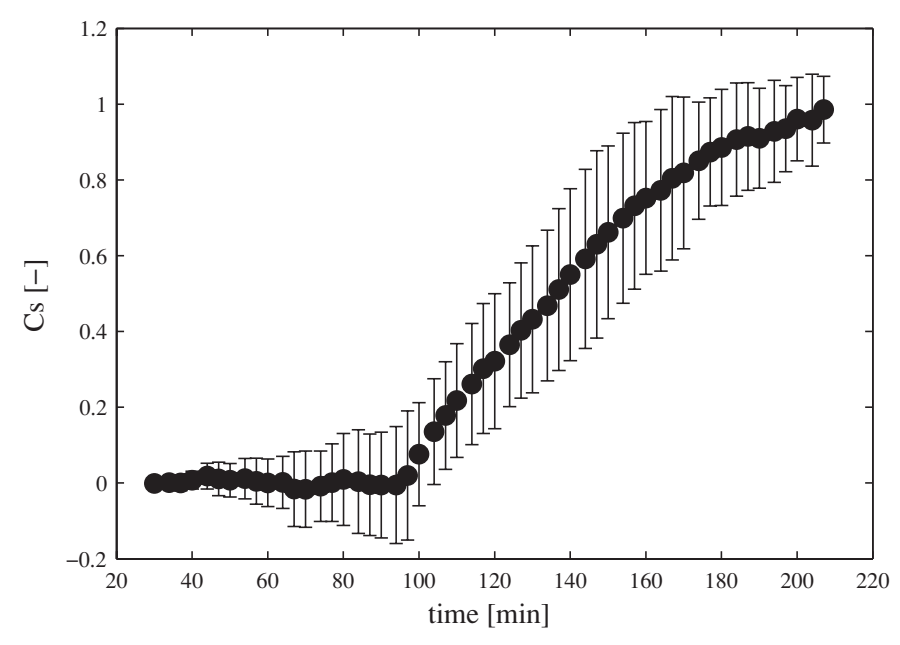

Figure 5. Mean Cs value of all subjects as a function of time (SD).

within an interthreshold zone, this classical approach is a good tool for developing predictive models (Mekjavic and Eiken 2006). An error signal is defined as the difference between the actual state of a variable $x$ and its setpoint $x_{0}: \Delta x=x-x_{0}$. It is known that the mean skin temperature responds reflexly on cutaneous vasoconstrictor tone (Wissler 2008) and can thus act as an innervating error signal. Lopez et al (1994) showed that vasoconstriction is also modulated by core temperature. According to Frank et al (1999) the core temperature to skin temperature contribution ratio to vasomotion is 3:1. Cheng et al (1995) reported that the cutaneous contribution of the mean skin temperature to vasoconstriction is linear with a core temperature to skin temperature contribution ratio of about $4: 1$. Therefore, it is possible to use the measured skin and core temperatures at each threshold to calculate a core-temperature threshold that would have been observed if the skin was at a standardized temperature (Matsukawa et al 1995):

$$
T_{\text {core, stand }}=T_{\text {core,obs }}+\left(\frac{\beta}{1-\beta}\right)\left(T_{\text {skin,obs }}-T_{\text {skin,stand }}\right) .
$$

Subscripts stand and obs denote standardized and observed (measured) temperature, respectively. Relation (10) was used for calculating the standardized core temperature at which vasoconstriction was triggered in the measurements. Here, we use $\beta=0.2$ and $T_{\text {skin,stand }}=35.7^{\circ} \mathrm{C}$ for vasoconstriction (values according to Matsukawa et al (1995) who based relation (10) on Cheng et al (1995)). The start of vasoconstriction was defined as the moment in time when $T_{\text {finger }}-T_{\text {forearm }}$ started to show a sustained decrease (see for an example figure 6).

At that time point, $T_{\text {core,obs }}$ was $36.9 \pm 0.4{ }^{\circ} \mathrm{C}$ and $T_{\text {skin,obs }}$ was $33.7 \pm 0.6^{\circ} \mathrm{C}$. Accordingly, $T_{\text {core, stand, } 0}$ was $36.4 \pm 0.4{ }^{\circ} \mathrm{C}$. The advantage of using the standardized core temperature as an error signal is that this structure can also be used in situations where the threshold of vasoconstriction $\left(T_{\text {core }, \text { stand, }, 0}\right)$ is shifted, for instance during motion sickness, fever and during anaesthesia.

Vasoconstrictor tone as a function of the error signal of the standardized core temperature is depicted in figure 7. From nonlinear regression analysis, the following relations were defined 


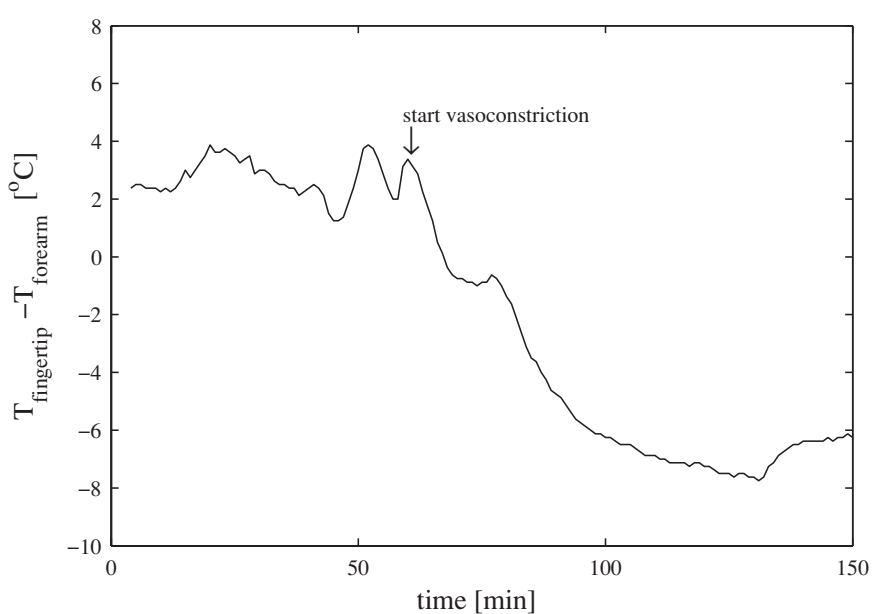

Figure 6. Typical example to illustrate the definition that was used to appoint the start point of vasoconstriction: time point where $T_{\text {fingertip }}-T_{\text {forearm }}$ shows a sustained decrease.

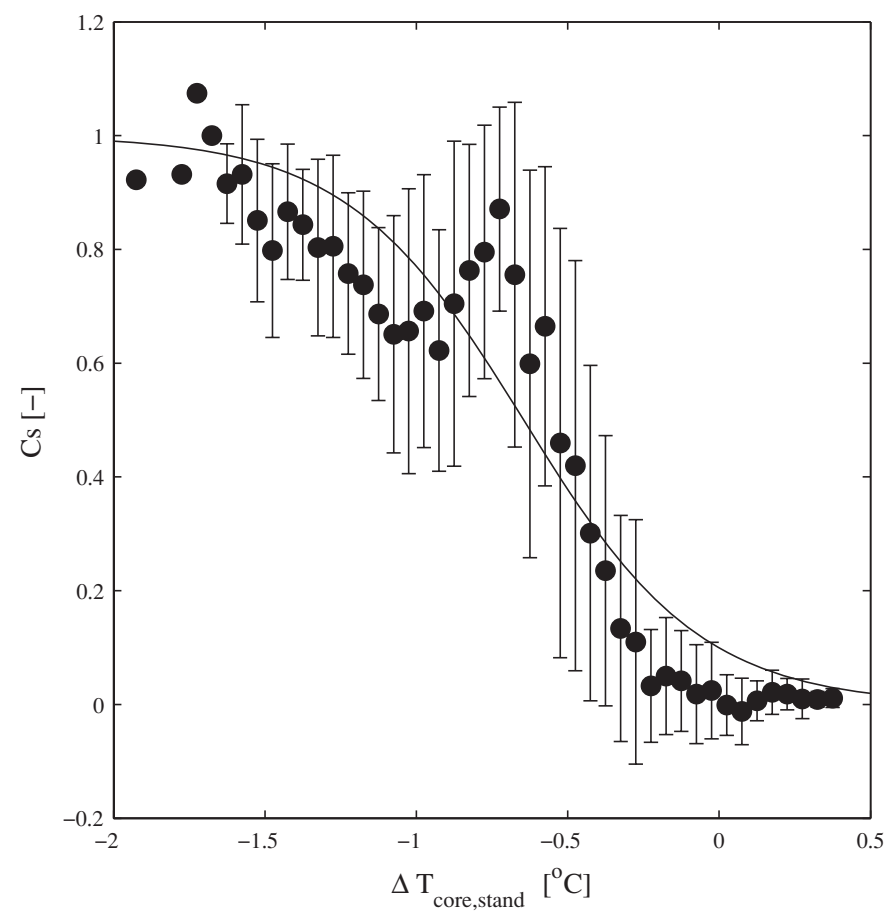

Figure 7. Mean Cs (SD) value as a function of the error of the standardized core temperature. The setpoint of the error signal was $T_{\text {core, stand, } 0}=36.4{ }^{\circ} \mathrm{C}$.

for the effect of the error at standardized core temperature $\left(\Delta T_{\text {core, stand }}=T_{\text {core,stand }}-T_{\text {core, stand, } 0}\right)$ on vasoconstriction tone $(\mathrm{Cs})$ :

$$
\mathrm{Cs}=0.5\left(1+\tanh \left(-1.71\left(\Delta T_{\text {core, stand }}+0.65\right)\right)\right)
$$


with $R^{2}=0.91$. The typical hyperbolic tangent shape was also used by Fiala et al (2001) and Wissler (2008) to describe cutaneous vasoconstriction, as the signal levels off. As can be seen in equation (11), the Cs values are bounded between 0 and 1.

\section{Discussion}

An experimental study was conducted to determine physiological values for vasoconstriction amplification coefficients and vasoconstrictor tone in the relation formulated by Stolwijk (1971). Vasoconstriction is a change of vessel diameter where the diameter becomes smaller. Earlier published models based vasoconstriction parameters either on estimations (Stolwijk 1971) or by fitting their models to global body temperature data (Gordon 1974, Fiala et al 2001). Those methods are very sensitive to errors and have a restricted physiological basis. Measuring capillary flow indirectly gives a measure for vasoconstriction. A measurement protocol was developed with which it was possible to derive vasoconstriction amplification coefficients and the transient vasoconstriction tone by measuring local perfusion and temperature.

The contributions to the normalized amplification coefficient from toe, leg and arm were $84 \%, 11 \%$ and $5 \%$, respectively. Comparing the normalized amplification values found in this study to the values from the literature displayed that the values of Stolwijk (1971) and Tanabe et al (2002) were within the standard deviation range of our experimentally determined values. The amplification coefficients employed by Fiala et al (2001) and Gordon (1974) deviated more from the current measured values.

Vasoconstriction thresholds are a linear function of skin and core temperature (Matsukawa et al 1995). Therefore, the error signal of the standardized core temperature was used as an input variable for deriving the vasoconstrictor tone relation. A baseline value for the standardized core temperature was found to be $\Delta T_{\text {core,stand, } 0}=36.6 \pm 0.4{ }^{\circ} \mathrm{C}$. This agrees well with the vasoconstriction threshold temperature observed by Matsukawa et al (1995), who found a value of $36.4 \pm 0.3{ }^{\circ} \mathrm{C}$. With the help of nonlinear regression analysis, a relation was formulated between the error signal of the standardized core temperature $\left(\Delta T_{\text {core,stand }}\right)$ and vasoconstrictor tone (Cs) for both methods. The advantage of using the standardized core temperature as an error signal is that this format can also be used under circumstances in which the threshold of vasoconstriction has changed, such as during anaesthesia (Severens et al 2007), during fever or during motion sickness. Then another value can be chosen as the setpoint for $T_{\text {core, stand, } 0}$ in equation (11).

A restriction of the presented work is that no time control measurement was performed; therefore, the effect of $3 \mathrm{~h}$ in the supine position on skin blood flow cannot be separated from the temperature effect. Furthermore, skin perfusion was measured only at three locations. Hence, a pilot experiment was designed in which values for $a_{\mathrm{cs}}$ for the other body parts were also assessed using the proposed method. For this protocol two subjects, who gave characteristic responses in the test, were selected. They underwent the same cycle lasting $3.5 \mathrm{~h}$ two times more. With the help of three laser Doppler flowmeters, with a total of five measurement channels, perfusion in the other body parts was assessed. The body parts that were remeasured gave comparable results for these two subjects. The results for $a_{\mathrm{cs}}$ that followed from the new experiments are given in table 6 .

To show the applicability of the experimental values for the local parameters, simulation with a whole body model was performed where the results of the developed vasoconstriction model were coupled to the model as described in Severens et al (2007). The active model results are compared to the predictions that are obtained when using only a passive model. The protocol as described in section 2.2 is resimulated with the help of the computer model. Simulations are run using group average body characteristics. In order to see the impact of the 


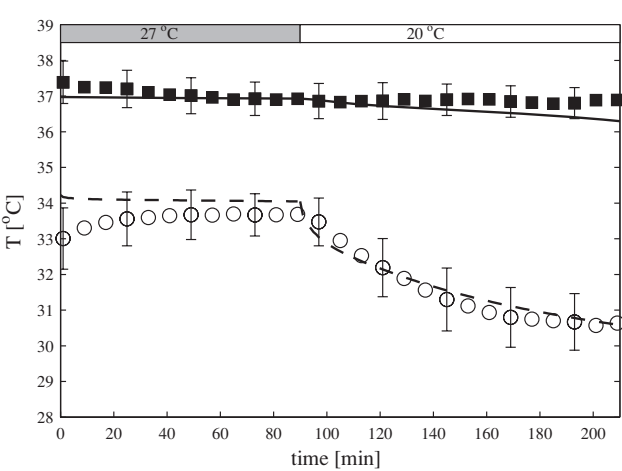

(a)

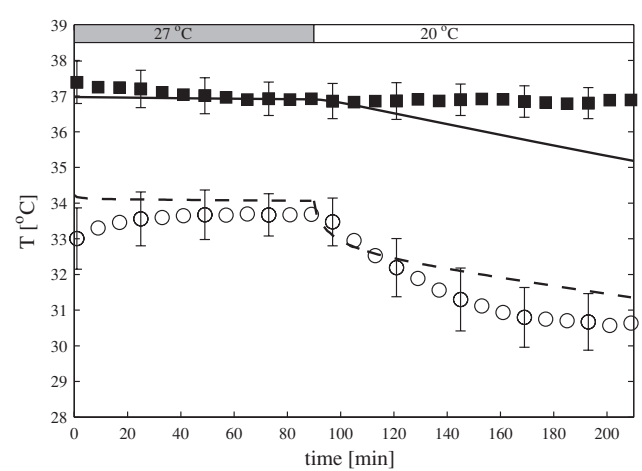

(b)

Figure 8. Warming-cooling cycle as described by the protocol in section 2.2 as calculated with (a) the local vasoconstriction values found in this study and with (b) the passive model. $\mathbf{\square}$ and $。$ represent the experimentally assessed core and mean skin temperatures, respectively; - and -represent the core and mean skin temperatures following from the simulation, respectively.

Table 6. Values for $a_{\mathrm{cs}}$ as found in the measurements.

\begin{tabular}{ll}
\hline Body part & $a_{\mathrm{cs}}$ \\
\hline Head & 0.48 \\
Face & 1.04 \\
Neck & 0.51 \\
Shoulder & 0.78 \\
Thorax & 0.33 \\
Abdomen & 1.05 \\
Hand & 2.47 \\
Arm $^{\mathrm{a}}$ & 7.42 \\
Leg $^{\mathrm{a}}$ & 1.00 \\
Foot $^{\mathrm{a}}$ & 0.46 \\
\hline
\end{tabular}

a Value based on $n=10$, see table 4 .

addition of the vasoconstriction model, simulations are also run without the vasoconstriction model. Results of the total model, including vasoconstriction and with only the passive model, are shown in figures 8(a) and (b), respectively.

It can be seen that core and mean skin temperature results of the simulation shown in figure 8(a) lie within the standard deviation interval of the mean temperature measurements, except for the core temperature in the last $10 \mathrm{~min}$. Here the simulated core temperature is $0.05-0.10{ }^{\circ} \mathrm{C}$ out of the standard deviation range of the measurements.

In figure $8(\mathrm{~b})$, it is seen that core temperature errors are very large when only the passive model is used. Core temperature errors in the last $5 \mathrm{~min}$ are around $1.8{ }^{\circ} \mathrm{C}$. Mostly, skin temperature is within the standard deviation range of the measurements, but is not as good as skin temperature predicted using the active model. Because of the lack of vasoconstriction, skin temperature in the cold predicted with the passive model is higher than in the model with the active part. 


\section{References}

Brenner I, Thomas S and Shephard R 1997 Spectral analysis of heart rate variability during heat exposure and repeated exercise Eur. J. Appl. Physiol. Occup. Physiol. 76 145-56

Chen Y, Lin Y, Jan I, Liu R, Chou N and Jan G 2004 Adaptive processing bandwidth adjustment for laser Doppler flowmetry Med. Biol. Eng. Comput. 42 277-81

Cheng C, Matsukawa T, Sessler D, Ozaki M, Kurz A, Merrifield B, Lin H and Olofsson P 1995 Increasing mean skin temperature linearly reduces the core-temperature thresholds for vasoconstriction and shivering in humans Anesthesiology 82 1160-8

Dubois D and Dubois E 1916 A formula to estimate the approximate surface area if height and weight be known Arch. Intern. Med. 17 863-71

Durnin J and Womersley J 1974 Body fat assessed from total body density and its estimation from skinfold thickness: measurements on 481 men and women aged from 16 to 72 years Br. J. Nutr. 32 77-97

Fiala D, Lomas K and Stohrer M 2001 Computer prediction of human thermoregulatory and temperature responses to a wide range of environmental conditions Int. J. Biometeorol. 45 143-59

Frank S, Raja S, Bulcao C and Goldstein D 1999 Relative contribution of core and cutaneous temperatures to thermal comfort and autonomic responses in humans J. Appl. Physiol. 86 1588-93

Gordon R 1974 The response of a human temperature regulatory system model in the cold PhD Thesis University of California, Santa Barbara

Hardy J and Stolwijk J 1966 Partitional calorimetric studies of man during exposures to thermal transients J. Appl. Physiol. 21 1799-806

Janssen F, Rajan V, Steenbergen W, Van Leeuwen G and Van Steenhoven A 2007 The relationship between local scalp skin temperature and cutaneous perfusion during scalp cooling Physiol. Meas. 28 829-39

Kellogg D, Morris S, Rodriguez S, Liu Y, Grossmann M, Stagni G and Shepherd A 1998 Thermoregulatory reflexes and cutaneous active vasodilation during heat stress in hypertensive humans J. Appl. Physiol. 85 175-80

Kernick D, Tooke J and Shore A 1999 The biological zero signal in laser Doppler fluximetry_origins and practical implications Pflugers Arch. 437 624-31

Leahy M, de Mul F, Nilsson G and Maniewski R 1999 Principles and practice of the laser-Doppler perfusion technique Technol. Health Care 7 143-62

Lopez M, Sessler D, Walter K, Emerick T and Ozaki M 1994 Rate and gender dependence of the sweating, vasoconstriction, and shivering thresholds in humans Anesthesiology 80 780-8

Matsukawa T, Kurz A, Sessler D, Bjorksten A, Merrifield B and Cheng C 1995 Propofol linearly reduces the vasoconstriction and shivering thresholds Anesthesiology 82 1169-80

Matsumoto T, Miyawaki C, Ue H, Kanda T, Yoshitake Y and Moritani T 2001 Comparison of thermogenic sympathetic response to food intake between obese and non-obese young women Obes. Res. 9 78-85

Mekjavic I and Eiken O 2006 Contribution of thermal and nonthermal factors to the regulation of body temperature in humans J. Appl. Physiol. 100 2065-72

Mitchell D and Wyndham C 1969 Comparison of weighting formulas for calculating mean skin temperature J. Appl. Physiol. 26 616-22

Obeid A, Barnett N, Dougherty G and Ward G 1990 A critical review of laser Doppler flowmetry J. Med. Eng. Technol. 14 178-81

Oida E, Moritani T and Yamori Y 1997 Tone-entropy analysis on cardiac recovery after dynamic exercise J. Appl. Physiol. 82 1794-801

Rubinstein E and Sessler D 1990 Skin-surface temperature gradients correlate with fingertip blood flow in humans Anesthesiology 73 541-5

Schoffelen F, Westerterp K, Saris W and Ten Hoor F 1997 A dual-respiration chamber system with automated calibration J. Appl. Physiol. 83 2064-72

Severens N 2008 Modelling hypothermia in patients undergoing surgery PhD Thesis Technische Universiteit Eindhoven

Severens N, Van Marken Lichtenbelt W, Frijns A, Van Steenhoven A, De Mol B and Sessler D 2007a A model to predict patient temperature during cardiac surgery Phys. Med. Biol. 52 5131-45

Severens N, Van Marken Lichtenbelt W, Van Leeuwen G, Frijns A, Van Steenhoven A, de Mol B, van Wezel H and Veldman D 2007b Effect of forced-air heaters on perfusion and temperature distribution during and after open-heart surgery Eur. J. Cardiothorac. Surg. 32 888-95

Stolwijk J 1971 A mathematical model of physiological temperature regulation in man NASA Contractor Report CR-1855 (Washington, DC: NASA)

Tanabe S, Kobayashi K, Nakano J, Ozeki Y and Konishi M 2002 Evaluation of thermal comfort using combined multi-node thermoregulation $(65 \mathrm{mn})$ and radiation models and computational fluid dynamics (CFD) Energy Build. 34 637-46 
Van Marken Lichtenbelt W, Daanen H, Wouters L, Fronczek R, Raymann R, Severens N and Van Someren E 2006 Evaluation of wireless determination of skin temperature using ibuttons Physiol. Behav. 88 489-97

Wissler E 2008 A quantitative assessment of skin blood flow in humans Eur. J. Appl. Physiol. 104 145-57

Zhong J, Seifalian A, Salerud G and Nilsson G 1998 A mathematical analysis on the biological zero problem in laser Doppler flowmetry IEEE Trans. Biomed. Eng. 45 354-64 